\title{
BMJ Open Impact of maternal smoking on early childhood health: a retrospective cohort linked dataset analysis of 697003 children born in Scotland 1997-2009
}

\author{
Richard Lawder, ${ }^{1}$ Bruce Whyte, ${ }^{2}$ Rachael Wood, ${ }^{1,3}$ Colin Fischbacher, ${ }^{1}$ \\ David Michael Tappin ${ }^{4}$
}

To cite: Lawder R, Whyte B, Wood R, et al. Impact of maternal smoking on early childhood health: a retrospective cohort linked dataset analysis of 697003 children born in Scotland 1997-2009. BMJ Open 2019;9:e023213. doi:10.1136/ bmjopen-2018-023213

- Prepublication history for this paper is available online. To view these files, please visit the journal online (http://dx.doi. org/10.1136/bmjopen-2018023213).

Received 11 April 2018 Revised 22 November 2018 Accepted 23 November 2018

Check for updates

(c) Author(s) (or their employer(s)) 2019. Re-use permitted under CC BY-NC. No commercial re-use. See rights and permissions. Published by BMJ.

${ }^{1}$ Information Services Division, NHS National Services Scotland, Edinburgh, UK

${ }^{2}$ Glasgow Centre for Population Health, University of Glasgow, Glasgow, UK

${ }^{3}$ Child Life and Health, University of Edinburgh, Edinburgh, UK

${ }^{4}$ Scottish Cot Death Trust, 5th

Floor, West Glasgow Ambulatory

Care Hospital, University of

Glasgow, Glasgow, UK

Correspondence to

Dr David Michael Tappin;

david.tappin@glasgow.ac.uk

\section{ABSTRACT}

Objective Smoking during pregnancy is associated with adverse health impacts on mother and child. We used a large linked Scottish dataset to produce contemporary estimates of the impact on child health, particularly hospitalisation.

Design Retrospective cohort study linking birth, death, maternity, infant health, child health surveillance and admission records. We examined the association between smoking status at maternity booking and pregnancy outcomes, hospital admission and death during the first 5 years of life. Models were adjusted for maternal age, socioeconomic status, infant feeding, country of birth, sex, parity and delivery mode. We calculated population attributable fraction (PAF) for each outcome.

Setting Scotland, UK.

Participants Singleton births between 1997 and 2009 ( $\mathrm{n}=697003)$ followed to March 2012.

Results 332386 children had at least one admission by 31 March 2012. There were 56588 born small for gestational age, 40492 prematurely and 1074 postneonatal deaths. Within the first 5 years of life, 56615 children had at least one admission for acute respiratory infections, 24088 for bronchiolitis and 7549 for asthma. Maternal smoking significantly increased admission for acute respiratory infections (adjusted $\mathrm{HR} 1.29,95 \% \mathrm{Cl}$ 1.25 to 1.34 , PAF $6.7 \%$ ) and bronchiolitis (HR 1.43, 95\% Cl 1.38 to 1.48 under 1 year, PAF 10.1\%), asthma (HR $1.29,95 \%$ Cl 1.22 to 1.37 age $1-5$ years, PAF $7.1 \%$ ) and bacterial meningitis (HR $1.49,95 \% \mathrm{Cl} 1.30$ to 1.71 , PAF $11.8 \%$ ) age $0-5$ years. Neonatal mortality (adjusted OR $1.32,95 \%$ Cl 1.17 to 1.49 , PAF $6.7 \%$ ), postneonatal mortality (OR 2.18, 95\% Cl 1.87 to 2.53, PAF $22.3 \%$ ), small for gestational age (OR $2.67,95 \% \mathrm{Cl} 2.62$ to 2.73 , PAF $27.5 \%$ ) and prematurity (OR $1.41,95 \% \mathrm{Cl} 1.37$ to 1.44 , PAF $8.8 \%$ ) were higher among the offspring of smokers.

Conclusion Smoking during pregnancy causes significant ill health and death among children born in Scotland. These findings support continued investment to reduce smoking among women before, during and after pregnancy as $50 \%$ of women will go on to have further children.
Strengths and limitations of this study

- Extensive dataset linkage allowed many outcomes to be assessed for each infant and inclusion of a control outcome to assess residual confounding.

- Use of smoking data collected only during pregnancy and lack of smoking data for $12 \%$ of the dataset.

- For $20 \%$ of records, maternal occupation was missing but balanced against this was the inclusion of three different measures of socioeconomic status (including maternal occupation, paternal occupation and deprivation Scottish Index of Multiple Deprivation score for area of maternal residence).

- Hospital admissions only were included and it is known that a large part of childhood morbidity is dealt with by Primary Care.

\section{INTRODUCTION}

\section{Background}

A total of 350 UK and 1100 US stillbirths each year are attributable to smoking during pregnancy $^{1}$ as are 200 UK and 900 US infant deaths. $^{2-4}$ Maternal smoking also increases a child's chance of being born prematurely with low birth weight, ${ }^{5}$ and having asthma, ${ }^{6}$ attention deficit disorder ${ }^{7}$ and learning difficulties, ${ }^{8}$ which if causally related all add substantial costs to healthcare. ${ }^{9}$ Pregnancy is also an opportunity to help most women quit smoking permanently before their own health is irreversibly compromised. Cessation during pregnancy if permanent reduces the likelihood of offspring becoming smokers, ${ }^{10}$ stopping mothers by example passing on their smoking habit to their children.

A fall in reported smoking during pregnancy has been reported in Scotland ${ }^{11}$ (20.8\% 2007, $15.5 \%$ 2015). In 2000, specific cessation services ${ }^{12}$ for pregnant women were established, supported by a National Institute for Health and Care Excellence guideline. ${ }^{13}$ However, self-reported smoking during 
and after pregnancy remains common. Twenty-five per cent of biochemically verified smokers self-report as non-smokers, ${ }^{14}$ and this proportion may be increasing as pressure to quit intensifies. Only $10 \%$ of pregnant smokers use cessation services in Scotland and as few as $3 \%$ quit during pregnancy. ${ }^{15}$ A recent report from the UK is more encouraging with on average $50 \%$ cessation during pregnancy. ${ }^{16}$

\section{Objectives}

We used a large linked Scottish dataset ${ }^{17}$ to produce contemporary estimates of the impact of maternal smoking measured in early pregnancy on pregnancy, infant and early child health outcomes. We focused on infant deaths and admissions to hospital for a range of conditions to assess the proportion of events attributable to smoking during pregnancy.

\section{METHODS}

\section{Study design, setting, participants, data sources}

This was a retrospective cohort study of singleton births in Scotland between 1997 and 2009 using anonymised extracts of linked administrative data provided by the Information Services Division, National Health Service National Services Scotland. Approval for the project design and confidentiality of patient data was provided by the Privacy Advisory Committee of NHS National Services Scotland, a body set up to ensure the appropriate use of patient identifiable information. ${ }^{18}$ Further ethical permission was not required. All 731595 live birth records in Scotland between the calendar years 1997 and 2009 inclusive were linked in two phases by probabilistic matching techniques including the use of the Community Health Index (CHI), a unique identifier developed for health records in Scotland. ${ }^{19}$ Phase 1 comprised linkage of births, deaths, migration, maternity, infant health and child health surveillance review records, ${ }^{20}$ which was extended in phase 2 to include all hospital admissions (ie, emergency admission and elective) from birth until death or up to March 2012. Thus, follow-up information on each child in the cohort was available for at least 2.25 years (for all children) and up to 15 years (depending on their birth year). The original cohort of 731595 births was reduced to 697003 as a result of excluding multiple births, babies of non-Scottish residents and duplicate linkage records.

\section{Outcome variables and bias}

The outcomes examined were neonatal and postneonatal mortality, pregnancy outcomes (infant small for gestational age and premature births) and hospital discharge up to the fifth birthday with a primary diagnosis from a list of conditions selected from a review of literature. Conditions of interest were asthma, bronchiolitis, bacterial meningitis, acute upper and lower respiratory infections, acute and chronic otitis media and mastoiditis and bronchopulmonary dysplasia. Emergency and planned admissions (with day cases) were included. Admissions for long bone fracture, not thought to be associated with maternal smoking, were used as a control outcome to assess if confounding had been satisfactorily controlled in the multivariate analysis.

\section{Definition of smoking during pregnancy}

Smoking behaviour in pregnancy is collected at a woman's first antenatal booking appointment which usually takes place within the first 3 months of pregnancy. These booking appointments take place either at hospital or in the community and are recorded on the Scottish WomanHeld Maternity Record. The smoking at booking information is subsequently transcribed onto the woman's Scottish Morbidity Record 02 which is submitted by the maternity units following delivery. The smoking behaviour is classified into either 'never smoked', 'current smoker', 'former smoker' or 'unknown/missing'.

\section{Statistical methods and quantitative variables}

Descriptive and univariate analyses were used to identify variables associated with smoking during pregnancy and perinatal, mortality and hospitalisation outcomes. Cox regression was used to quantify the independent contribution of maternal smoking to hospitalisation outcomes, based on survival from birth to the earliest of first hospitalisation, death, migration, the fifth birthday or the end of the observation period (March 2012). Logistic regression was used for perinatal and mortality outcomes. The models included variables identified from directed acyclic graphs as potentially biassing (confounding) the association between smoking and the relevant outcomes. Adjustment was made for maternal age, maternal and paternal socioeconomic status, infant feeding at $6-8$ weeks, country of birth, infant sex, parity, mode of delivery and quintile of the Scottish Index of Multiple Deprivation (SIMD). Each Cox regression model was tested for proportionality using inspection of log-log plots. Additional analysis was conducted to assess the risk of hospitalisation for long bone fractures (a condition not causally associated with maternal smoking), to test the adequacy of adjustment for socioeconomic and demographic confounders included in the linked dataset. Statistical modelling was carried out using Stata V.11; StataCorp LP.

Population attributable fractions (PAFs) were used to quantify the number of outcome events that would have been avoided if no women had smoked, using the formula:

$$
P A F=\frac{P_{c}(R R-1)}{R R}
$$

where $\mathrm{RR}$ is the relative risk and $\mathrm{P}_{\mathrm{c}}$ is the proportion of cases exposed to the risk factor.

Patient or public involvement

No patient or public involvement. 


\section{RESULTS}

\section{Participants}

Of the 697003 singletons born between 1997 and 2009 included in the analysis (table 1), $63 \%$ were born by spontaneous vaginal delivery, $8 \%$ had teenage mothers, $16 \%$ were born to single parents or parents living apart, $44 \%$ were born to first-time mothers and $25 \%$ were residents in the most socioeconomically deprived quintile. Twenty-three per cent of infants had mothers who smoked (table 1). A total of $332386(48 \%)$ had at least one hospital admission by 31 March 2012 (figure 1).

\section{Descriptive data}

As previously reported, ${ }^{17}$ there was a greater relative risk of hospital admission among infants resident in more deprived areas, of fathers and mothers with a semiroutine/routine occupation, of babies bottle fed or combination fed (bottle and breast), among infants with siblings, and those born by Caesarean delivery. Conversely, risk of infant admission decreased with increasing maternal age, among female infants and if a mother's country of birth was non-British. ${ }^{17}$ During the study period, 87877 $(12.6 \%)$ infants were hospitalised at least once for one of the selected conditions in the first 5 years (figure 1). At the first recorded hospital event for any of the selected conditions, $43 \%$ were under 1 year of age, and $57 \%$ were between first and fifth birthday. Most of these first hospital events were 'emergency admissions' (91\%), especially among infants less than 1 year of age at admission (99\%).

Younger unmarried pregnant women and women from deprived postcode areas and socioeconomic circumstances were more likely to be current smokers, as were British born compared with non-British born pregnant women (table 1). Smoking varied little by mode of delivery or number of previous children, however, babies who were bottle fed, or whose mother's religion was Christian or Jewish were more likely to have mothers who were current smokers at maternity booking (table 1).

\section{Outcome data}

The crude rate of hospitalisation (any cause) per 1000 person-years was 141 among infants born to mothers who smoked, 108 for those who did not smoke, 119 for former smokers and 109 for those with missing smoking status (data not shown in tables or figure).

\section{Main results}

Multivariate analyses

We start with the most devastating outcomes.

\section{Perinatal and mortality outcomes and smoking status at first booking}

Among babies whose mothers were current smokers at hospital booking, the odds of neonatal mortality (in first month after birth) were a third higher than among non-smokers after taking account of confounding variables (OR 1.32, 95\% CI 1.17 to 1.49 , PAF $6.7 \%$ table 2). The odds of postneonatal infant mortality (between 1 month and 1 year of age) were 2.18 times higher if the mother smoked (PAF 22.3\%). The odds of being born small for gestational age was 2.67 times higher for current smokers (PAF 27.5\%) while the odds of premature delivery were also significantly increased (OR 1.41, 95\% CI 1.37 to 1.44 , PAF $8.8 \%$ ).

Rates of hospitalisation for acute respiratory infections, bronchiolitis and asthma

Because of non-proportional hazards for these conditions over the whole period of follow-up, hazard ratios (HRs) are presented separately for the first year of the life and the subsequent 4 years (table 3 ). During the first year of life, the adjusted HR for hospital admission for acute respiratory infections was increased by $29 \%$ (PAF $6.7 \%$ ), by $43 \%$ (PAF 10.1\%) for bronchiolitis and more than doubled for asthma among infants of mothers who smoked. For the period from the first birthday to the age of 5 , there were more modest increases in hazards for asthma (adjusted $\mathrm{HR}=1.29, \mathrm{PAF}=7 \%$ ) and for bronchiolitis (adjusted $\mathrm{HR}=1.16, \mathrm{PAF}=4 \%$ ) but no increase in hazard of acute respiratory infections.

\section{Rates of hospitalisation for meningitis, ear infections and chronic} lung disease

For children of mothers who were current smokers during pregnancy, the rate of hospitalisation in the first 5 years of life was substantially raised compared with non-smokers for bronchopulmonary dysplasia $(50 \%$ increase, PAF $10.1 \%)$ and for bacterial meningitis (49\% increase, PAF $11.8 \%$, table 4$)$. There was only a small increase in the rate of hospitalisation with acute and chronic otitis media and mastoiditis (7\% increase, PAF 1.7\%).

\section{Other analyses}

Hospital admissions related to long bone fractures were analysed as a control group. There were 5757 children admitted for long bone fractures from the cohort during the study period. After adjustment for other factors (maternal age, maternal and paternal socioeconomic status, infant feeding at $6-8$ weeks, country of birth, infant sex, parity, mode of delivery and quintile of the SIMD), a mother being a smoker at maternity booking was not a significant predictor of hospital admission for long bone fractures.

\section{DISCUSSION}

This study of Scottish births (1997-2009) provides more detailed evidence about the association between maternal smoking in pregnancy and childhood hospitalisation as well as birth conditions which can lead to lifelong ill health and devastating outcomes such as meningitis. This study also estimates the proportion of babies born prematurely, small for gestational age and infant deaths that were attributable to maternal smoking during pregnancy. These associations remain significant after adjustment for a range of socioeconomic factors. 
Table 1 Cohort characteristics of maternal smoking at maternity booking usually in early pregnancy: Scottish births in period 1997-2009

\begin{tabular}{|c|c|c|c|c|c|c|}
\hline & \multicolumn{2}{|l|}{ Cohort } & \multicolumn{4}{|c|}{ Smoking at first booking } \\
\hline & $\mathbf{N}$ & Column \% & $\begin{array}{l}\text { Never smoked } \\
\text { (row \%) }\end{array}$ & $\begin{array}{l}\text { Current smoker } \\
\text { (row \%) }\end{array}$ & $\begin{array}{l}\text { Former smoker } \\
\text { (row \%) }\end{array}$ & $\begin{array}{l}\text { Status unknown } \\
\text { (row \%) }\end{array}$ \\
\hline All woman & 697003 & 100 & 56 & 23 & 9 & 12 \\
\hline \multicolumn{7}{|l|}{ Babies gender } \\
\hline Male & 347399 & 50 & 58 & 24 & 9 & 10 \\
\hline Female & 330241 & 47 & 58 & 24 & 9 & 10 \\
\hline Missing & 19363 & 3 & 0 & 0 & 0 & 100 \\
\hline \multicolumn{7}{|l|}{ Maternal age (years) } \\
\hline Less than 20 & 55843 & 8 & 36 & 41 & 11 & 11 \\
\hline $20-24$ & 127265 & 18 & 44 & 34 & 10 & 12 \\
\hline $25-29$ & 186949 & 27 & 57 & 22 & 9 & 11 \\
\hline $30-34$ & 202008 & 29 & 64 & 16 & 8 & 12 \\
\hline $35-39$ & 103457 & 15 & 65 & 15 & 7 & 13 \\
\hline $40+$ years & 18848 & 3 & 64 & 16 & 6 & 14 \\
\hline Invalid & 2633 & 0 & 0 & 0 & 0 & 100 \\
\hline \multicolumn{7}{|l|}{ Area deprivation (quintiles) } \\
\hline Most deprived & 173490 & 25 & 41 & 38 & 8 & 13 \\
\hline 2 & 140730 & 20 & 51 & 28 & 9 & 12 \\
\hline 3 & 129649 & 19 & 58 & 21 & 9 & 12 \\
\hline 4 & 129072 & 19 & 65 & 14 & 9 & 12 \\
\hline Least deprived & 124048 & 18 & 73 & 8 & 7 & 12 \\
\hline Missing & 14 & 0 & 43 & 21 & 7 & 29 \\
\hline \multicolumn{7}{|l|}{ Mother's country of birth } \\
\hline Non-British & 57334 & 8 & 69 & 9 & 6 & 17 \\
\hline British & 639647 & 92 & 55 & 24 & 9 & 12 \\
\hline Not Known & 22 & 0 & 41 & 32 & 9 & 18 \\
\hline \multicolumn{7}{|l|}{ Mother's occupation } \\
\hline Managerial/professional & 187513 & 27 & 71 & 9 & 7 & 13 \\
\hline Intermediate & 156848 & 23 & 63 & 15 & 9 & 12 \\
\hline Semiroutine/routine & 200774 & 29 & 46 & 33 & 10 & 11 \\
\hline Students & 11885 & 2 & 51 & 24 & 10 & 14 \\
\hline Other/not known & 139983 & 20 & 44 & 36 & 7 & 13 \\
\hline \multicolumn{7}{|l|}{ Father's occupation } \\
\hline Managerial/professional & 198936 & 29 & 71 & 9 & 7 & 13 \\
\hline Intermediate & 116614 & 17 & 63 & 16 & 8 & 12 \\
\hline Semiroutine/routine & 309886 & 44 & 49 & 30 & 10 & 12 \\
\hline Students & 7112 & 1 & 59 & 17 & 7 & 17 \\
\hline Other/not known & 64455 & 9 & 34 & 44 & 8 & 14 \\
\hline \multicolumn{7}{|l|}{ Marital status } \\
\hline Cohabiting & 202610 & 29 & 44 & 33 & 11 & 13 \\
\hline $\begin{array}{l}\text { Single/parents living } \\
\text { apart }\end{array}$ & 113254 & 16 & 34 & 44 & 9 & 13 \\
\hline Married & 381139 & 55 & 69 & 11 & 7 & 12 \\
\hline \multicolumn{7}{|l|}{ Parity } \\
\hline No siblings/first child & 309769 & 44 & 57 & 22 & 10 & 11 \\
\hline
\end{tabular}


Table 1 Continued

\begin{tabular}{|c|c|c|c|c|c|c|}
\hline & \multicolumn{2}{|l|}{ Cohort } & \multicolumn{4}{|c|}{ Smoking at first booking } \\
\hline & $\mathbf{N}$ & Column \% & $\begin{array}{l}\text { Never smoked } \\
\text { (row \%) }\end{array}$ & $\begin{array}{l}\text { Current smoker } \\
\text { (row \%) }\end{array}$ & $\begin{array}{l}\text { Former smoker } \\
\text { (row \%) }\end{array}$ & $\begin{array}{l}\text { Status unknown } \\
\text { (row \%) }\end{array}$ \\
\hline One or more siblings & 363374 & 52 & 59 & 25 & 7 & 9 \\
\hline Other/unknown & 23860 & 3 & 12 & 4 & 2 & 82 \\
\hline \multicolumn{7}{|l|}{ Infant feeding at $6-8$ weeks } \\
\hline Both & 46877 & 7 & 65 & 13 & 8 & 14 \\
\hline Bottle & 342483 & 49 & 50 & 29 & 9 & 12 \\
\hline Breast & 144124 & 21 & 70 & 9 & 8 & 13 \\
\hline Invalid/unknown & 163519 & 23 & 55 & 25 & 9 & 12 \\
\hline \multicolumn{7}{|l|}{ Mode of delivery } \\
\hline Normal/spontaneous & 440632 & 63 & 56 & 26 & 9 & 9 \\
\hline $\begin{array}{l}\text { Instrumental/breech } \\
\text { births }\end{array}$ & 85143 & 12 & 61 & 19 & 10 & 10 \\
\hline $\begin{array}{l}\text { Caesarean (elective/ } \\
\text { emergency) }\end{array}$ & 151537 & 22 & 60 & 20 & 9 & 11 \\
\hline $\begin{array}{l}\text { Other/unknown/no data } \\
\text { recorded }\end{array}$ & 19691 & 3 & 1 & 0 & 0 & 98 \\
\hline \multicolumn{7}{|c|}{ Maternal religious background } \\
\hline Buddhist & 4186 & 1 & 72 & 3 & 4 & 22 \\
\hline Christian & 663563 & 95 & 55 & 24 & 9 & 12 \\
\hline Hindu & 1848 & 0 & 75 & 5 & 2 & 18 \\
\hline Jewish & 432 & 0 & 50 & 26 & 9 & 15 \\
\hline Muslim & 18057 & 3 & 79 & 4 & 2 & 15 \\
\hline Sikh & 1697 & 0 & 82 & 3 & 2 & 14 \\
\hline Non-applicable & 7220 & 1 & 58 & 18 & 7 & 17 \\
\hline
\end{tabular}

\section{Key results}

Increased postneonatal mortality

More than 20\% of postneonatal deaths, many of which will be defined as Sudden Unexpected Deaths in Infancy, ${ }^{21}$ would probably have been avoided if mothers had not smoked during pregnancy. This result is consistent with the findings of a study of over 3 million births in the USA which reported a $40 \%$ higher infant mortality among the children of mothers who smoked, with a dose-dependent relationship with the number of cigarettes smoked. ${ }^{22}$ An analysis of Swedish birth registry data which adjusted for a range of confounders found an increased risk of neonatal mortality. $^{23}$

Increased risk of small for gestational age

Births that are small for gestational age are associated with long-term ill health including hypertension and obesity, and $27.5 \%$ of these were attributable to maternal smoking. These findings are consistent with a number of large studies that have found associations between maternal smoking and intrauterine growth retardation. ${ }^{23} 24$

Increased risk of bacterial meningitis

The rare but life-threatening condition-bacterial meningitis-was $49 \%$ more likely to occur among $0-5$ years old children born to mothers who smoked, making $11.8 \%$ of cases attributable to smoking during pregnancy. This increase in an infectious disease outcome has been described before for infections in the first year of life including meningitis. ${ }^{25}$ Several studies have reported an increased risk of meningococcal disease including meningitis among the children of mothers who smoke. ${ }^{26-28}$

Increased risk of admission for acute upper and lower respiratory infections, asthma and wheezing as well as bronchiolitis

The proportion of hospital admissions attributable to maternal smoking for common infant and child conditions including bronchiolitis $(10.1 \%)$, and upper and lower respiratory infections $(6.7 \%)$ in the first year of life, and asthma $(7.1 \%)$ age $1-5$ years are both statistically and, more importantly, clinically significant. These results are consistent with the findings from other studies that have reported an increased risk of hospital admission for bronchiolitis among the children of mothers who smoked during pregnancy. ${ }^{29}$ Several reviews have found an association between maternal smoking and the subsequent development of wheezing or asthma among children. ${ }^{30}$ Two large case-control studies reported by Metzger et al found that maternal smoking was associated with an 


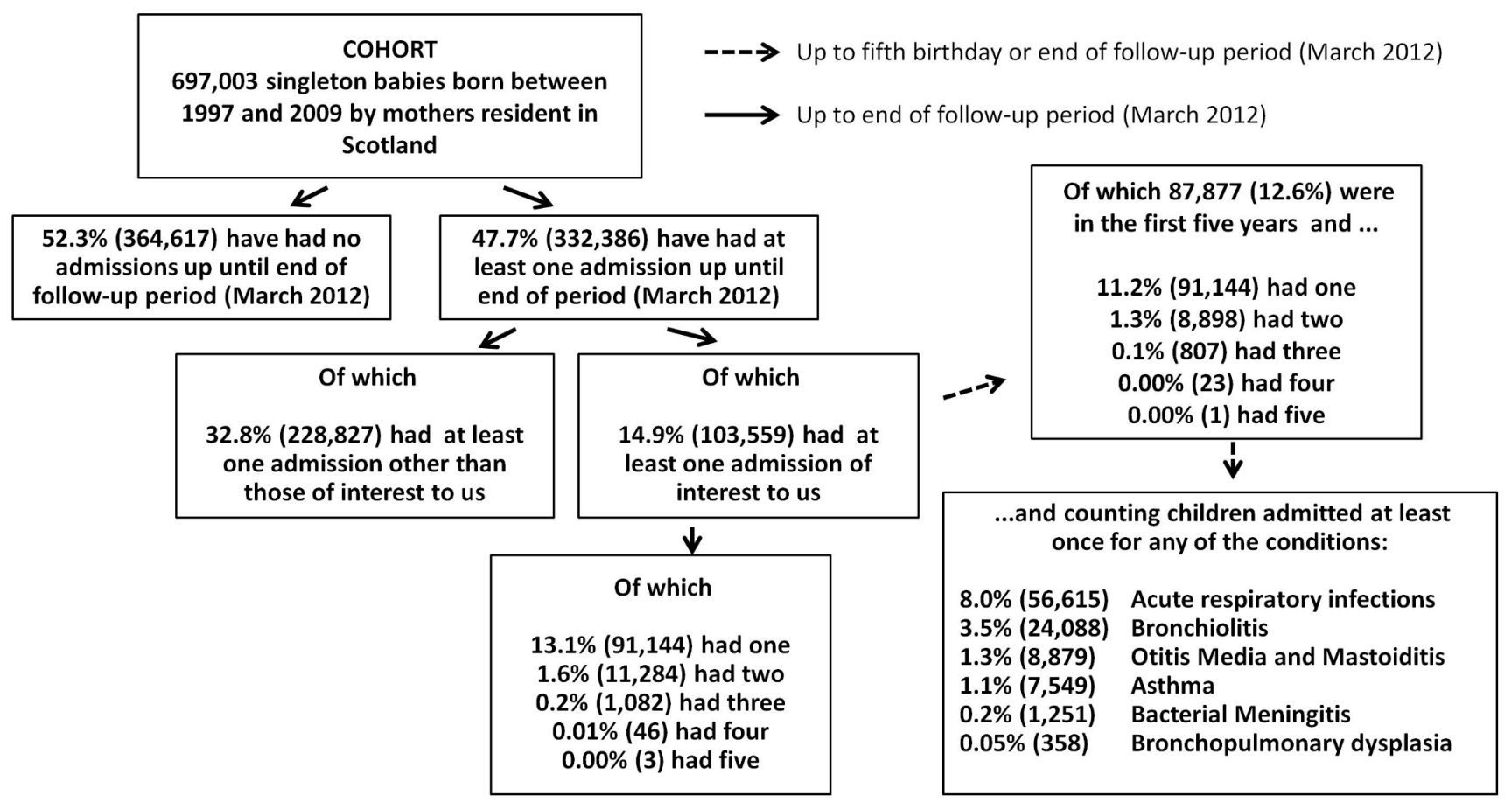

Figure 1 Admissions to hospital for children born in Scotland between 1997 and 2009.

increased risk of hospitalisation for infectious disease, including a $69 \%$ increase in the odds of hospitalisation for respiratory infection. ${ }^{25}$

\section{Strengths and limitations}

Other similar studies generally only looked at one or two outcomes, ${ }^{31}$ for example, birth outcomes (small for gestational age and stillbirth) usually derived from a single dataset. ${ }^{32}$ It is the linkage of routinely collected datasets that sets this study apart, allowing, in this case, hospitalisation outcomes to be gathered over time. This is possible in Scotland because the excellent routine data collection systems allow data linkage between separate datasets on all infants and their mothers. ${ }^{19}$ Data linkage will only be improved by widespread use of the CHI, a unique identifier (https://www.ndc.scot.nhs.uk/Dictionary-A-Z/Definitions/index.asp? ID=128\&Title $=\mathrm{CHI}$ ), now given to every baby in Scotland which can be linked to the mothers' CHI number. Future linkage studies will provide a powerful tool with many research and surveillance applications to support improved healthcare and surveillance for the population of Scotland.

In addition, in our study, we modelled hospitalisations for long bone fractures-not causally associated with maternal smoking - to act as a control outcome. This analysis suggests that the adjustment for socioeconomic confounders was sufficient.

Smoking behaviour in pregnancy was collected as self-reported data at a woman's first antenatal booking appointment which usually takes place within the first 3 months of pregnancy. We know that $25 \%$ of current smokers at maternity booking do not admit to their smoking habit. ${ }^{14}$ We also know that: "Although many women quit smoking during their pregnancy, relapse rates are high and most start smoking again within 6 months of giving birth'. ${ }^{13}$ Both these issues would suggest that true smokers were in the non-smoker category in our analysis. This will have reduced our overall estimates of PAF. Therefore, the figures we have calculated are likely to be an underestimate of real effects of maternal smoking on outcomes. This study only looked at babies who were born alive and therefore does not include pregnancy outcomes leading to fetal death, that is, early miscarriage or stillbirth, both of which are devastating and are associated with maternal smoking. ${ }^{1333} 34$ This study focussed on hospitalisation of infants and children to 5 years of age, and therefore does not include older child illnesses or those only requiring support from primary care. This may explain the low PAF for otitis media, as children are treated in primary care and only rarely admitted to hospital. It also excluded short-term and long-term consequences of smoking for the mother herself where continued smoking will shorten life by on average 10 years. ${ }^{35}$ Maternal smoking information was recorded as unknown or missing for $12 \%$ of individuals in the cohort. Pregnancy and mortality outcomes were significantly worse within this group, suggesting that perhaps unrecorded smoking or another unknown risk factor was important.

Although the coverage and completeness of variables using the routine datasets was relatively high, the study was limited by the availability of confounders on the linked dataset and uncertainty over the overall duration of maternal smoking. We do, however, know that few women who self-report as smokers at maternity booking quit during or probably after pregnancy. ${ }^{15}$ In addition, 
Table 2 Likelihood of specific perinatal and mortality outcomes and smoking status at first booking

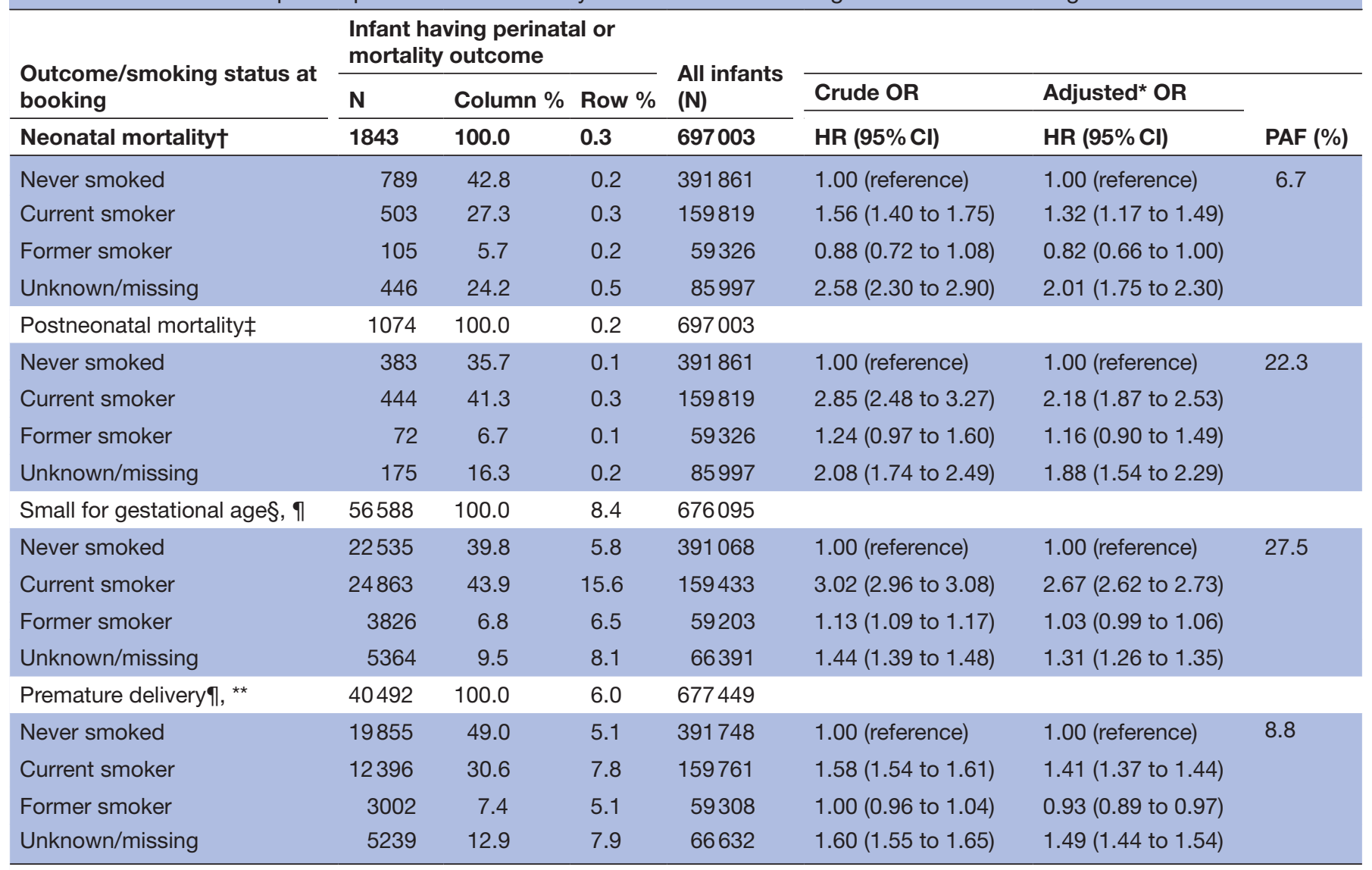

*Adjusted for: maternal age; infant gender, SIMD; mothers socioeconomic status; fathers socioeconomic status; parity; mode of delivery and country of birth.

†Neonatal mortality describes a baby that has died during the first 28 days of life.

$\ddagger$ Postneonatal mortality is defined as those infant deaths in which the infant is more than 28 days and less than 1 year of age.

§Under 10th centile-small for gestational age.

ๆUnknown/missing data excluded from modelling.

**Birth of a baby at fewer than 37 weeks gestational age.

PAF, population attributable fraction; SIMD, Scottish Index of Multiple Deprivation.

an important limitation of this study is that there was a high level of missing data for some of the variables used, particularly infant feeding method and maternal occupation. This is likely to relate to the phased introduction of the Child Health Surveillance Programme across Scotland during the study period which has been recognised for infant feeding data. The impact of missing data on maternal occupation may not have been significant because of the inclusion of the two other measures of socioeconomic level in the regression models: area deprivation and paternal occupation.

\section{Interpretation}

Overall, it is likely that there is an underestimation of the association between maternal smoking and poor outcomes including hospitalisation as $25 \%$ of pregnant smokers deny their habit when asked at maternity booking. ${ }^{14}$ This level of under-reporting may increase the attributable fraction for each condition by a third, making, for example, the proportion of small for gestational age babies attributable to maternal smoking $36 \%$ rather than $27.5 \%$. Alternatively, if those with missing smoking data were all smokers, the estimates we present would be reduced. However, our analysis of 'small for gestational age' (table 2)the most well-known effect of maternal smoking during pregnancy-does not suggest that all those with missing smoking data are in fact current smokers. The OR for 'unknown/missing' smoking status is $1.31(1.26,1.35)$ and for 'current smoker' is 2.67 (2.62, 2.73).

This study adds to the evidence identifying key adverse childhood outcomes of maternal smoking.

Maternal smoking is still making a substantial contribution to poor pregnancy outcomes and morbidity in early childhood.

This study confirms previous findings that maternal smoking is associated with large increases in the risks of being small for gestational age, of postneonatal mortality and of premature delivery, but less evidence of impact on neonatal mortality. 


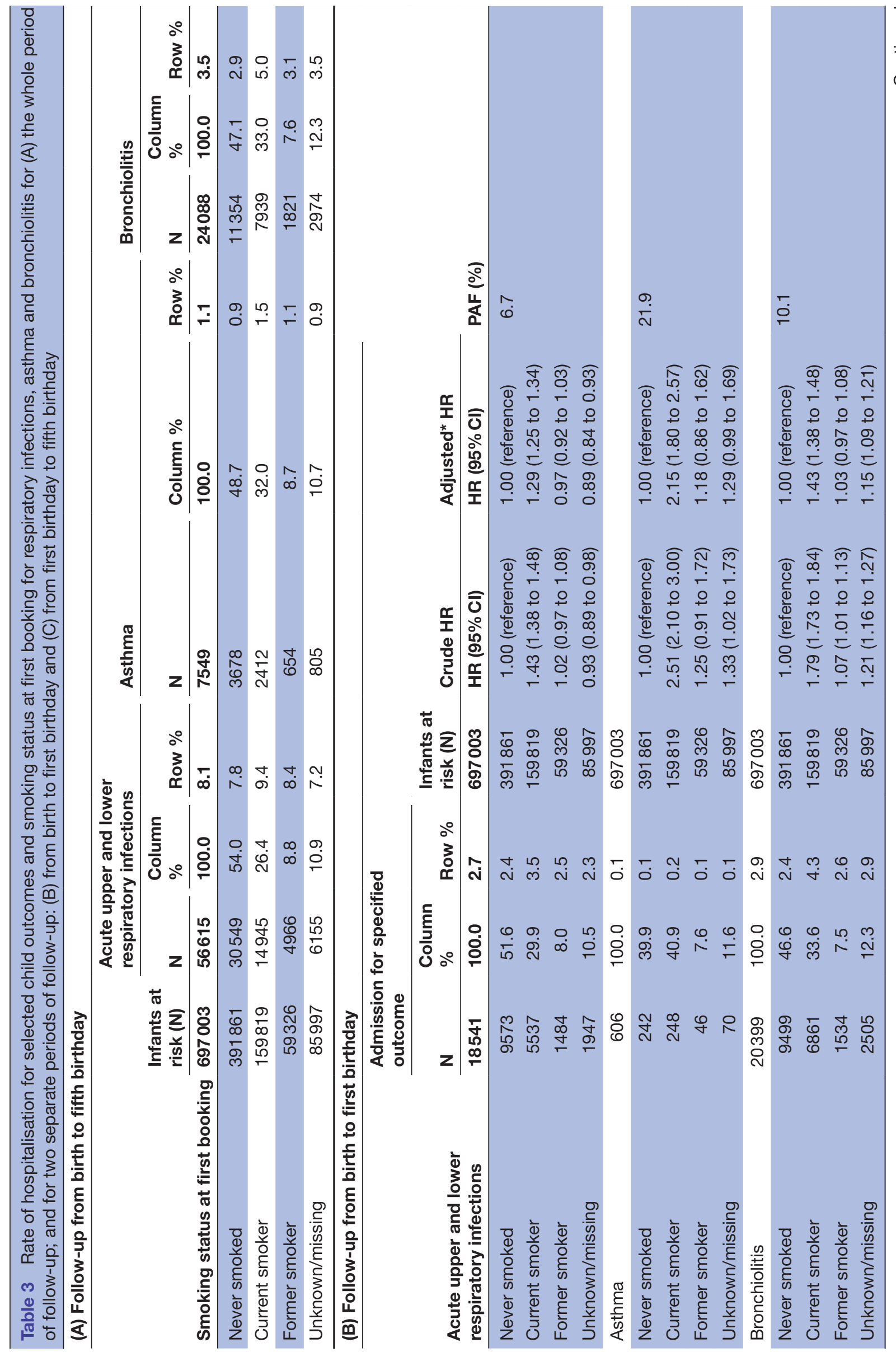




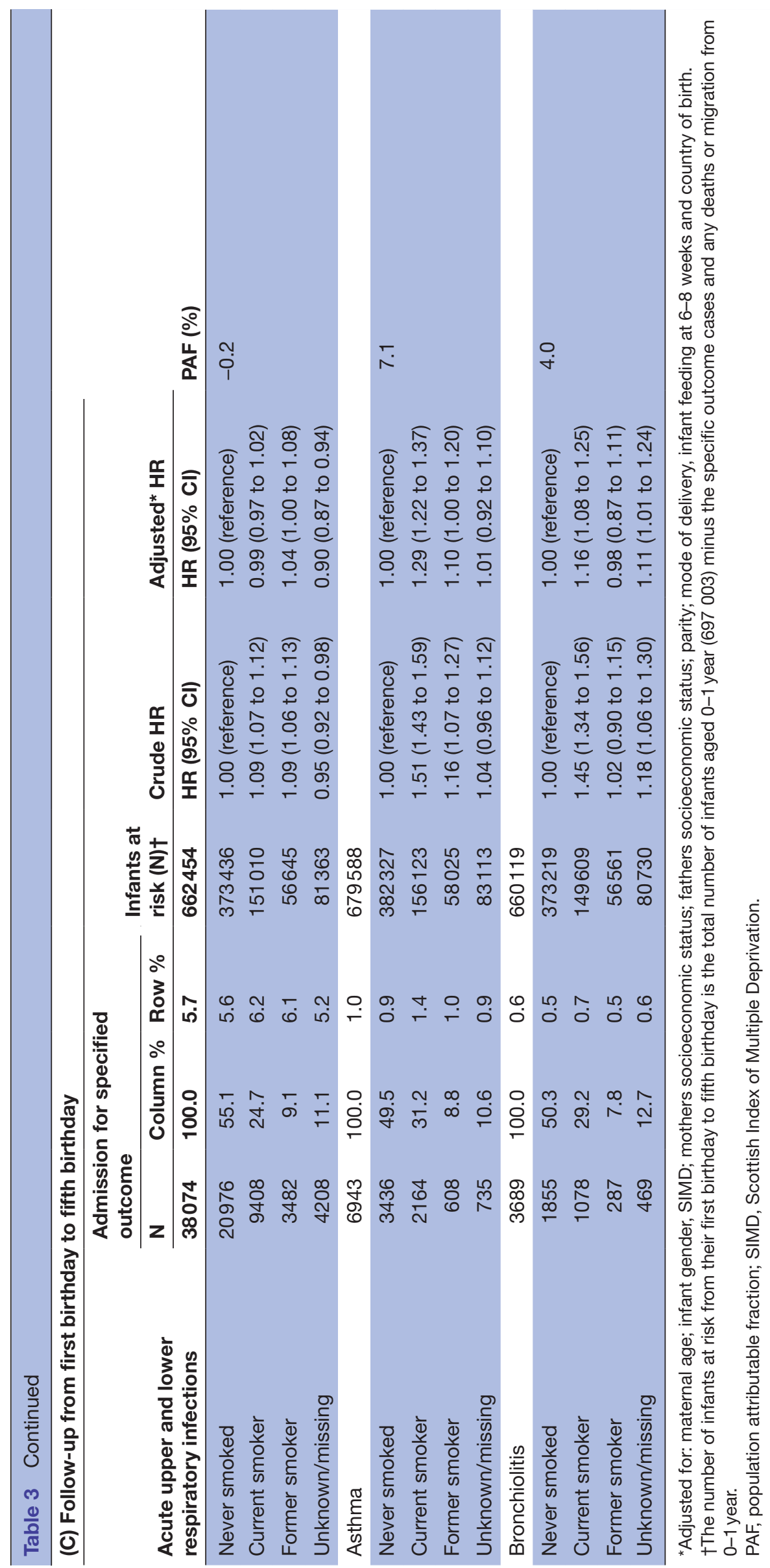


Table 4 Likelihood of specific perinatal and mortality outcomes and smoking status at first booking

\begin{tabular}{|c|c|c|c|c|c|c|c|}
\hline $\begin{array}{l}\text { Smoking status at } \\
\text { first booking }\end{array}$ & $\mathbf{N}$ & $\begin{array}{l}\text { Column } \\
\%\end{array}$ & Row \% & All infants (N) & Crude HR & Adjusted* HR & \\
\hline Bacterial meningitis & 1251 & 100.0 & 0.2 & 697003 & HR $(95 \% \mathrm{Cl})$ & HR $(95 \% \mathrm{Cl})$ & PAF (\%) \\
\hline Never smoked & 525 & 42 & 0.1 & 391861 & 1.00 (reference) & 1.00 (reference) & 11.8 \\
\hline Current smoker & 450 & 36 & 0.3 & 159819 & 2.09 (1.84 to 2.37$)$ & $1.49(1.30$ to 1.71$)$ & \\
\hline Former smoker & 125 & 10 & 0.2 & 59326 & 1.57 (1.29 to 1.91$)$ & 1.35 (1.11 to 1.64$)$ & \\
\hline Unknown/missing & 151 & 12 & 0.2 & 85997 & 1.34 (1.11 to 1.60$)$ & 1.29 (1.06 to 1.57$)$ & \\
\hline $\begin{array}{l}\text { Acute and chronic otitis } \\
\text { media and mastoiditis }\end{array}$ & 8879 & 100.0 & 1.3 & 697003 & & & \\
\hline Never smoked & 4866 & 55 & 1.2 & 391861 & 1.00 (reference) & 1.00 (reference) & 1.7 \\
\hline Current smoker & 2148 & 24 & 1.3 & 159819 & 1.05 (1.00 to 1.11$)$ & 1.07 (1.02 to 1.14$)$ & \\
\hline Former smoker & 755 & 9 & 1.3 & 59326 & 1.02 (0.94 to 1.10$)$ & 1.01 (0.94 to 1.10$)$ & \\
\hline Unknown/missing & 1110 & 13 & 1.3 & 85997 & 1.10 (1.03 to 1.18$)$ & 1.13 (1.06 to 1.22$)$ & \\
\hline $\begin{array}{l}\text { Bronchopulmonary } \\
\text { dysplasia }\end{array}$ & 358 & 100.0 & 0.1 & 697003 & & & \\
\hline Never smoked & 141 & 39 & 0.0 & 391861 & 1.00 (reference) & 1.00 (reference) & 10.1 \\
\hline Current smoker & 109 & 30 & 0.1 & 159819 & 1.90 (1.48 to 2.44$)$ & 1.50 (1.15 to 1.96$)$ & \\
\hline Former smoker & 22 & 6 & 0.0 & 59326 & 1.03 (0.66 to 1.61$)$ & 0.90 (0.57 to 1.42$)$ & \\
\hline Unknown/missing & 86 & 24 & 0.1 & 85997 & 2.79 (2.13 to 3.65$)$ & 3.21 (2.45 to 4.22 ) & \\
\hline Long bone fracture & 5757 & 100.0 & 0.8 & 697003 & & & \\
\hline Never smoked & 3156 & 55 & 0.8 & 391861 & 1.00 (reference) & 1.00 (reference) & -1.5 \\
\hline Current smoker & 1466 & 25 & 0.9 & 159819 & $1.11(1.04$ to 1.18$)$ & 0.94 (0.88 to 1.01$)$ & \\
\hline Former smoker & 532 & 9 & 0.9 & 59326 & 1.11 (1.01 to 1.21$)$ & 1.06 (0.96 to 1.16$)$ & \\
\hline Unknown/missing & 603 & 10 & 0.7 & 85997 & 0.93 (0.85 to 1.02$)$ & 0.92 (0.83 to 1.01$)$ & \\
\hline
\end{tabular}

*Adjusted for: maternal age; infant gender, SIMD; mothers socioeconomic status; fathers socioeconomic status; parity; mode of delivery, infant feeding at 6-8 weeks and country of birth.

PAF, population attributable fraction; SIMD, Scottish Index of Multiple Deprivation.

Meningitis, bronchopulmonary dysplasia, asthma, bronchiolitis and acute upper and lower respiratory infections (in the first year of life) make large contributions to the increased risk of hospital admission; ear infections are less prominent, probably because nearly all are treated in primary care, though still a significant risk.

The strength of the association between maternal smoking and increased infant and child morbidity and mortality, consistent with other studies, provides convincing evidence of the benefits of maternal smoking abstinence on child health.

\section{Generalisability}

This study presents results from a 'whole population' cohort of infants born in Scotland over a 13-year period from 1997 to 2009. Children have been followed through to March 2012. These results are contemporary and are likely to generalise to most other UK countries and other countries with high levels of smoking during pregnancy.

Acknowledgements Omotomilola Ajetunmobi, Information Services Division, NHS National Services Scotland, Edinburgh, Scotland, UK who created the dataset with BW for the breastfeeding and hospitalisation analysis.
Contributors All authors helped plan this study. RL analysed the data and commented on the manuscript drafts. CF supervised RL and commented on the manuscript drafts. DMT wrote the manuscript. BW commented on the manuscript drafts and helped create the database. RW commented on the manuscript drafts.

Funding The authors have not declared a specific grant for this research from any funding agency in the public, commercial or not-for-profit sectors.

Competing interests None declared.

Patient consent for publication Not required.

Provenance and peer review Not commissioned; externally peer reviewed.

Data sharing statement № additional unpublished data are available from the study.

Author note Technical appendix, statistical code and dataset available from: Information Services Division NHS National Services Scotland, Edinburgh, Scotland.

Open access This is an open access article distributed in accordance with the Creative Commons Attribution Non Commercial (CC BY-NC 4.0) license, which permits others to distribute, remix, adapt, build upon this work non-commercially, and license their derivative works on different terms, provided the original work is properly cited, appropriate credit is given, any changes made indicated, and the use is non-commercial. See: http://creativecommons.org/licenses/by-nc/4.0/.

\section{REFERENCES}

1. Flenady V, Koopmans L, Middleton P, et al. Major risk factors for stillbirth in high-income countries: a systematic review and metaanalysis. Lancet 2011;377:1331-40. 
2. ONS (Office for National Statistics). Infant and perinatal mortality in England and Wales by social and biological factors.Stat Bull 2011, Key findings. www.ons.gov.uk/ons/dcp171778_300596.pdf

3. Dietz PM, England LJ, Shapiro-Mendoza CK, et al. Infant morbidity and mortality attributable to prenatal smoking in the U.S. Am J Prev Med 2010;39:45-52.

4. Health Inequalities Unit, Department of Health. Review of the Health Inequalities Infant. Mortality PSA Target 2007; www.perinatal.nhs.uk/ smoking/health\%20inequalities\%20report\%202007.pdf

5. Delpisheh A, Kelly Y, Rizwan S, et al. Population attributable risk for adverse pregnancy outcomes related to smoking in adolescents and adults. Public Health 2007;121:861-8.

6. Gilliland FD, Li YF, Peters JM. Effects of maternal smoking during pregnancy and environmental tobacco smoke on asthma and wheezing in children. Am J Respir Crit Care Med 2001;163:429-36.

7. Button TM, Maughan B, McGuffin P. The relationship of maternal smoking to psychological problems in the offspring. Early Hum Dev 2007;83:727-32.

8. Batstra L, Hadders-Algra M, Neeleman J. Effect of antenatal exposure to maternal smoking on behavioural problems and academic achievement in childhood: prospective evidence from a Dutch birth cohort. Early Hum Dev 2003;75(1-2):21-33.

9. Godfrey C, Pickett KE, Parrot S, et al. Estimating the costs to the NHS of smoking in pregnancy for pregnant women and infants, 2010. http://phrc.Ishtm.ac.uk/papers/PHRC_A3-06_Final_Report. pdf

10. Leonardi-Bee J, Jere ML, Britton J. Exposure to parental and sibling smoking and the risk of smoking uptake in childhood and adolescence: a systematic review and meta-analysis. Thorax 2011;66:847-55.

11. ISD Scotland website. Smoking History and Booking. http://www. isdscotland.org/Health-Topics/Maternity-and-Births/Publications/ data-tables.asp?id=1791\#1791

12. NHS Executive. New NHS Smoking Cessation Services. Health Service Circular, 1999. http://www.dh.gov.uk/prod_consum_dh/ groups/dh_digitalassets/@dh/@en/documents/digitalasset/dh_ 4011979.pdf (accessed on 29 July 2011).

13. NICE (National Institute for Health and Care Excellence). Smoking: stopping in pregnancy and after childbirth, 2010. Public Health Guidance 26. https://www.nice.org.uk/guidance/ph26

14. Shipton D, Tappin DM, Vadiveloo T, et al. Reliability of self reported smoking status by pregnant women for estimating smoking prevalence: a retrospective, cross sectional study. BMJ 2009;339:b4347.

15. Tappin DM, MacAskill S, Bauld L, et al. Smoking prevalence and smoking cessation services for pregnant women in Scotland. Subst Abuse Treat Prev Policy 2010;5:1.

16. HSCIC (Health and Social Care Information Centre). Infant feeding survey - 2010. 2011. http://www.hscic.gov.uk/catalogue/PUB00648

17. Ajetunmobi OM, Whyte B, Chalmers J, et al. Breastfeeding is associated with reduced childhood hospitalization: Evidence from a scottish birth cohort (1997-2009). J Pediatr 2015;166:620-5.
18. National Privacy Advisory Committee. http://www.nhsnss.org/pages/ corporate/privacy_advisory_committee.php (Accessed Aug 2013).

19. Fleming $\mathrm{M}$, Kirby $\bar{B}$, Penny $\bar{K}$. Record linkage in Scotland and its applications to health research. J Clin Nurs 2012;21:2711-21.

20. Ajetunmobi $O$, Whyte B, Chalmers J, et al. Informing the 'early years' agenda in Scotland: understanding infant feeding patterns using linked datasets. J Epidemiol Community Health 2014;68:83-92.

21. ISD Scotland. Stillbirths and infant deaths. http://www.isdscotland. org/health-Topics/Maternity-and-Births/Stillbirth-and-Infant-Deaths/

22. Salihu HM, Aliyu MH, Pierre-Louis BJ, et al. Levels of excess infant deaths attributable to maternal smoking during pregnancy in the United States. Matern Child Health J 2003;7:219-27.

23. Källén K. The impact of maternal smoking during pregnancy on delivery outcome. Eur J Public Health 2001;11:329-33.

24. Baba S, Wikström AK, Stephansson O, et al. Changes in snuff and smoking habits in Swedish pregnant women and risk for small for gestational age births. BJOG 2013;120:456-62.

25. Metzger MJ, Halperin AC, Manhart LE, et al. Association of maternal smoking during pregnancy with infant hospitalization and mortality due to infectious diseases. Pediatr Infect Dis J 2013;32:e1-e7.

26. Goldacre MJ, Wotton CJ, Maisonneuve JJ. Maternal and perinatal factors associated with subsequent meningococcal, Haemophilus or enteroviral meningitis in children: database study. Epidemiol Infect 2014;142:371-8.

27. Sørensen HT, Labouriau R, Jensen ES, et al. Fetal growth, maternal prenatal smoking, and risk of invasive meningococcal disease: a nationwide case-control study. Int J Epidemiol 2004;33:816-20.

28. Yusuf HR, Rochat RW, Baughman WS, et al. Maternal cigarette smoking and invasive meningococcal disease: a cohort study among young children in metropolitan Atlanta, 1989-1996. Am J Public Health 1999;89:712-7.

29. Koehoorn M, Karr CJ, Demers PA, et al. Descriptive epidemiological features of bronchiolitis in a population-based cohort. Pediatrics 2008;122:1196-203.

30. Ferrante $\mathrm{G}$, Antona $\mathrm{R}$, Malizia $\mathrm{V}$, et al. Smoke exposure as a risk factor for asthma in childhood: a review of current evidence. Allergy Asthma Proc 2014;35:454-61.

31. Mund M, Louwen F, Klingelhoefer D, et al. Smoking and pregnancy-a review on the first major environmental risk factor of the unborn. Int $J$ Environ Res Public Health 2013;10:6485-99.

32. Erickson AC, Arbour LT. Heavy smoking during pregnancy as a marker for other risk factors of adverse birth outcomes: a populationbased study in British Columbia, Canada. BMC Public Health 2012;12:102-11.

33. Centers for Disease Control and Prevention. PRAMStat. 2011. http:// nccd.cdc.gov/PRAMStat/rdPage.aspx?rdReport=DRH_PRAMS. ExploreByTopic\&is $\mid$ Class $|d=C L A 9 \& i s|$ Topicld $=$ TOP27\&go=GO

34. ONS. Office for National Statistics). Infant and perinatal mortality in England and Wales by social and biological factors. Stat Bull 2011. Key findings www.ons.gov.uk/ons/dcp171778_300596.pdf

35. Doll R, Peto R, Boreham J, et al. Mortality in relation to smoking: 50 years' observations on male British doctors. BMJ 2004;328:1519. 